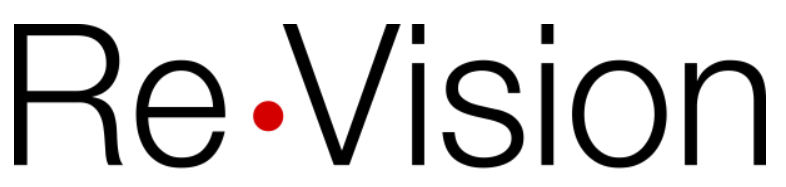

UNIVERSITY

of GUELPH

The Centre for Art and Social Justice

\title{
Difference-Attuned Witnessing: Risks and Potentialities of Arts-Based Research
}

Carla Rice

University of Guelph

Katie Cook

Wilfrid Laurier University

K. Alysse Bailey

University of Guelph

This is a post-peer-review, pre-copyedit version of an article published in Feminism \& Psychology. The final authenticated version is available online at: https://doi.org/10.1177/0959353520955142

\section{Recommended citation:}

Rice, C., Cook, K., \& Bailey, K. A. (2020). Difference-attuned witnessing: Risks and potentialities of arts-based research. Feminism \& Psychology. https://doi.org/10.1177/0959353520955142 


\section{Difference-Attuned Witnessing: Risks and Potentialities of Arts-Based Research}

Carla Rice, Katie Cook, and K. Alysse Bailey

\section{Abstract}

In this paper, we interrogate notions of affect, vulnerability and difference-attuned empathy, and how they relate to bearing witness across difference-specifically, connecting through creativity, experiencing the risks and rewards of vulnerability, and witnessing the expression of difficult emotions and the recounting of affect-imbued events within an arts-based process called digital/multi-media storytelling (DST). Data for this paper consists of 63 process-oriented interviews conducted before and after participants engaged with DST in a research project focused on interrogating negative concepts of disability that create barriers to healthcare. These retrospective reflections on DST coalesce around experiences of vulnerability, relationality, and the risks associated with witnessing one's own and others' selective disclosures of difficult emotions and affect-laden aspects of experiences of difference. Through analyzing findings from our process-oriented interviews, we offer a framework for understanding witnessing as a necessarily affective, difference-attuned act that carries both risk and transformative potential. Our analysis draws on feminist Indigenous (Maracle), Black (Nash) and affect (Ahmed) theories to frame emerging concepts of affective witnessing across difference, difference-attuned empathy, and asymmetrical vulnerability within the arts-based research process. 


\section{Key Words}

Difference-attuned witnessing, digital/multi-media storytelling, difference-attuned empathy, leaning in, asymmetrical vulnerability, disability and difference, Canada

This paper frames the workshop spaces created through the arts-based methodology of digital/multi-media storytelling (DST) as ephemeral, affective communities with acts of difference-attuned witnessing and empathy at their core. We present a rich conceptualization of difference-attuned witnessing in the DST space as an affective and a potentially transformative process that recognizes power and difference while providing opportunities for meaningful connection. This methodology was developed by the $\mathrm{Re} \cdot$ Vision Centre for Art and Social Justice, a research creation centre that investigates the power of the arts to influence decision-makers and imagine more just futures (Rice et al., 2017, 2018, 2020a). Across research projects, we work to create spaces in which interchange about difference, power, and oppression becomes possible, by bringing together minoritized and majoritized storytellers, including those located in systems (education, healthcare) implicated in minoritized groups' alienation and oppression (Rice \& Mündel, 2018; Douglas et al., 2020). This approach responds to the urgent need for new kinds of social science methods to address persistent, deepening social inequities; we hold that in our neoliberal, hyper-individual, and highly polarized world, arts and storytelling methods hold potential for making dialogue across social problems and uneven power relations possible, but do this in ways that do not erase power, collapse difference or ignore the psychic and material effects of systemic harms (Douglas et al., 2019; Rice et al., 2020b; Rice \& Mündel, 2019). 
The current study seeks to deepen conceptualizations of affective witnessing-a witnessing that fosters "the radical embrace of connectedness" (Nash, 2019, p. 118) by examining how affective witnessing shows up in DST. Drawing from and extending Richardson and Schankweiler's (2019) understanding of affective witnessing as an inherently relational and bodily act, we theorize ethical engagements across difference by analysing the ways that relationalities form and bodies perform through differenceattuned witnessing and empathy. We consult feminist Indigenous, Black and affect theorists whose work points to the centrality of attuning to embodied (and embedded) difference in affective spaces such as in interactions between tellers (subjects) and the listener/receivers (witnesses) in research processes. We also engage with Richardson and Schankweiler's (2019) insight into how increased availability of digital technologies (e.g. smartphones) provides opportunities for events to be witnessed at a later time, separate from the event, by co-witnesses. "As the temporality of witnessing blurs-the time of the event, the time of the viewing, the times of circulation," they write, "so too do its affective dynamics" (p. 166). Our study examines the affective dynamics of witnessing across difference in arts-based research, specifically multimedia/digital storytelling workshops on experiences of disability in healthcare, where the methodology plays a key role in the affective dynamics of how a participant's account is witnessed, when, and by whom.

We draw on the theory work of Indigenous feminists who analyze the intricacies of attending closely to others' accounts. Joanne Archibald (1997) (Sto:lo) writes that within Indigenous oral cultures the listener/teller/story relationship is a critical principle of storytelling that emphasizes inter-relationality by implicating the listener into becoming 
an active participant in interpreting a story. Here the relationship between story, teller, and listener requires listeners/receivers to think actively about their context and self in relation to the story being told and to consider how their subjectivity might impact the story they hear and the meaning they make, all the while questioning how the telling itself might affect and contour their perceptions of themselves, others, and the relationship. Writing about the egregious treatment of Indigenous peoples in Canada, Lee Maracle (2015) (Sto:lo) describes listening/receiving as an embodied, affective, and spiritual act, a cross-sensory perception that involves in/direct speech, non-verbal sounds, and haptic and kinesthetic engagement (igniting a witness's sense of touch and movement), whereby the viewer/listener/receiver's body is connected to the dynamics of attending to. This suggests that bearing witness to oppression, as a relational practice, requires the active engagement of viewers/listeners in ways that carry the potential to re/shape and re/define the contours of self and other, and the affectively charged space between.

Feminist affect theory helps us to theorize encounters across power and difference by analyzing how affect shapes the very surfaces of bodies-individual and collective (Ahmed, 2004). Sarah Ahmed argues that we are largely shaped by the contact that we have with others; and she theorizes contact as emotional-sensorial forces that circulate across, within, and between bodies that phenomenologically shape ours' and others' embodied experiences and inform meanings we make of these. Her analysis helps to explain the non-discursive (sensory, embodied) flows of power in encounters and as such, offers insights for theorizing the affective dimensions of witnessing across difference. Black feminist Jennifer Nash $(2013,2019)$ brings affect 
theory to bear on the praxis of testifying and witnessing across raced bodies in her critique of intersectionality politics and counterproposal of love politics. Nash (2013) offers two main criticisms of intersectional politics as currently practiced: 1) they treat identity as fixed and 2) they imagine change as possible only within the confines of existing social movements and only amongst those who already share similar understandings of oppression and visions of liberation. Speaking back to these enactments, Nash's love politics seeks to move Black feminism from a focus on the "wounded Black female self" (2013, p. 3) toward a radical embrace of difference in the face of fear and anxiety, ultimately creating affective, difference-attuned communities with the potential to become sites of redress with an orientation toward the future. Bearing witness-or difference-attuned, affect-oriented witnessing, as we explore in this paper-is one way in which affective communities manifest surrounding shared and unique experiences.

We engage feminist Indigenous, Black and affect writers whose work grapples with the knowability of the experience of others. We recognize that Indigenous and Black scholars confront different forms of oppression related to settler colonization and white supremacy and respond in their own culturally unique and politically rooted ways to these structural inequities. We further acknowledge that settler colonization and white supremacy are interlinked systems that together uphold white power structures, which perpetuate the devaluation, domination, "exclusion and premature death of people of color in settler colonial states" (Bonds \& Inwood 2016, p. 716), oftentimes through the debilitation (structural disabling) of Black and Indigenous populations. In this context, we understand witnessing to be an active and affective practice whereby listening/viewing 
subjects become "entangled in a complex web of relations" (Richardson \& Schankweiler, 2019, p. 166) and argue that at its core, witnessing within webs of uneven power (such as ablest, white supremacist, settler colonial healthcare systems) necessarily entails opening radically to experiences of difference. We understand difference-attuned witnessing as a practice whereby witnesses attend closely to embodied and embedded knowledge rooted in story and embrace their responsibilities for transforming inequitable relations beyond their immediate worlds (e.g. beyond the research space). We frame the DST workshop as a collective space that holds the possibility of becoming a difference- and an affectively attuned community through the witnessing practices built into the methodology.

\section{Ethical Engagements across Difference}

Theorizing the dynamics of affective communities and the act of bearing witness requires exploration of critical literatures on what constitutes ethical engagement across difference and what we mean by witnessing itself. Across disciplines, approaches to difference are complex, and suggestive of diverse frameworks for increasing understanding, forging relationships, and bearing witness, particularly when aiming to do so in politically and ethically intentional and potentially transformational ways. We focus our analysis on methods for engaging across difference offered in social justice scholarship. Following our commitments to feminist decolonizing praxis, we emphasize the feminist practice of transversalism (Yuval-Davis, 1997) and the Indigenous practice of leaning into ethical space (Maracle, 2015; Ermine, 2007). 
Transversalism (Yuval-Davis, 1997) was developed as a way to speak back to the second wave feminist praxis of universalism, which, in assuming that all women shared similar experiences, privileged gender as the key locus of oppression over other categories of difference. According to sociologist Niva Yuval-Davis, transversalism emerged in the 1990s as a difference-responsive praxis among feminists in Europe who were working on responding to violence against women across ethnicity, race, class, and refugee/immigrant/citizenship status. They developed a relational process of first rooting in their own histories, positionalities, and implicatedness in current conditions and then shifting to understand the histories, positionalities, and conditions of suffering/resistance of others as a method for creating difference-sensitive feminism. Rooting, as a necessary starting point, requires one to critically reflect on one's own history, embodied experiences, and positions of power/marginalization before turning to understand others' experiences (Rice, 2009, 2018). The process of rooting and shifting might be thought of as a witnessing practice in how it aims to honour the space between self and other by avoiding attempts to collapse difference (the claim that 'everyone is the same'); appropriate difference (the desire to become the other), eliminate difference (the assertion that difference is problematic) or overcome difference (the assumption difference does or should not matter). Transversalism engages instead with questions of privilege, oppression, belonging, and beyond (Rice, 2009, 2018). Some scholars have noted that while transversal praxis remains valuable, it is limited by its rootedness in standpoint epistemology, or the idea that our knowledge is shaped by our unique experiences and is therefore only ever partial and limited. The difficulty with practicing transversalism is that our capacity to understand our own histories and positionalities is 
limited by the premise of standpoint theory itself, for "if all our knowledge is limited by our experiences, our self-knowledge must also be limited" including the ways that our positionalities may be implicated in causing harm (Rice et al., 2019, p. 416). To mitigate the shortcomings of transveralism, we turn to Indigenous and Black feminist practices of ethical engagement that stress a radical opening to (rather than a definitive knowing of) the other.

The kind of ethical engagement that emerges from the work of Indigenous and Black feminist writers emphasizes attending closely or listening with all one's senses. Here, listening does not precisely equate with aurality (and hence does not exclude d/Deaf people), but rather encompasses seeing, perceiving, feeling, sentience-a relational, embodied witnessing of the other. As Maracle explains, "My listening is sentient, a total body experience. I trust my body to imbibe the words, to swallow them, commit to them, take the words on a journey through my body and then discipline my response to them" (2015, p. 21). Other Indigenous feminist scholars have described the act of attending closely with one's embodied being as a generative (Carter, 2015) relational process (Recollet, 2015). Beyond embodied engagement, this mode of leaning-in to listen-perceive-learn (in line with transversalism) requires of the receiver a willingness to recognize their implication in the psychic and material impacts of inequities under investigation. Indigenous scholar Willie Ermine (Cree, 2007) describes such an encounter as creating ethical space-a space of possibility between self and other, where ethical engagement or co-witnessing that acknowledges and honours difference can take place. For Ermine, ethical space "offers a venue to step out of our allegiances, to detach from the cages of our mental worlds and assume a position 
where human-to-human dialogue can occur" (p. 202). Both transversalism and ethical space ask us to reject notions of universalism and approach the moral and affective thresholds of ourselves and others-to bear witness across our differences.

These approaches to difference raise critical questions about the tools, such as empathy, that psychology has historically used to understand and attune with those who are (or have been) wronged. Outside the discipline, the critical literature on empathy is varied and contentious. For critical pedagogy scholar Megan Boler (1997), empathy is a risky process that threatens to consume and annihilate the other through identification with the other's pain. That is, in the process of claiming to know what the other is feeling, I must put myself in the other's position and make a judgement about what the other needs in order to flourish. In Boler's (1999) view, empathy requires that I (the empathizer) must consume the other's pain and make it my own, thus failing to come to know the other. Empathy, therefore, risks decontextualizing moral issues of injustice (Boler, 1999). Writing in the context of reading empathetically, Boler $(1997,1999)$ suggests instead the justice-oriented concept of testimonial reading, where empathy leads to a responsibility for action. Testimonial reading, for Boler, requires an understanding of historical context and power relations that are inherent in the reader/text dynamic. Similarly, feminist philosopher Judith Butler (2004) argues that empathy risks collapsing, rather than honouring, the space between self and other.

Others exploring how empathic identifications can be ethical, political, and transformational, ask: "In what ways might empathy work to unsettle privilege, reveal the dynamics of power relations, encourage individual and collective reflexivity, and stimulate political action?" (Gray, 2011, p. 208). Sociologist Breda Gray's notion of 
empathy is contingent on the full, affective recognition of a respected other rather than the collapse of self/other. Similarly, in her work on allyship, Colleen McGloin (2015) suggests listening to hear as a tool for ethical alliances, particularly as listening as a tool relates to non-Indigenous witnesses to Indigenous testimony. Allyship requires a pedagogy of discomfort, whereby colonial histories are re-visited/re-told. This political listening, or listening to hear, requires de-centring the self in order to imagine the other in context-an uneasy, unsettling, necessary aspect of political listening (or attending closely) that supersedes apolitical notions of empathy via identification (McGloin, 2015). Following Gray (2011), we approach empathy as one of the catalyzers of the connections that form between individuals in affective, attuned-to-difference communities. Our understanding, alternatively referred to as heteropathic empathy by Silverman (1996), does not rely upon collapsing difference and annihilating alterity in the process of enacting empathy, but rather keeps difference at the heart of identification. While the idea of heteropathic empathy is relevant, we note that the root pathic suggests suffering and victimhood-notions that could be used to pathologize and marginalize. Instead, we use the term difference-attuned empathy to refer to a practice of empathy that holds difference and ethical engagement at the heart of the connection.

\section{Testimony and Response}

We differentiate the various forms and uses of testimony and witnessing, for example in a legal sense, witness testimony is judged on its truth value and ability to hold up under external scrutiny (Oliver, 2004). In a historical context, testimony is used to describe witness accounts of acts of war, genocide, and disaster (Mansbach, 2016). 
On a more intimate level, bearing witness describes interpersonal interactions whereby an individual's testimony regarding their lived experiences is witnessed by another, or within a small group (Oliver, 2004). Ethically witnessing across differences requires moving beyond recognition and identification to address and response (Oliver, 2015). The act of witnessing and responding requires one to open oneself up to the affective flows that circulate and the bonds that form relationally between witness and witnessed (Ahmed \& Stacey, 2001; Richardson \& Shankweiler, 2019). The affective character of witnessing creates vulnerabilities whereby one party is exposed to another. We must then ask: what is gained from the act of witnessing? Whose stories are made visible and heard, and at what cost? And finally, how and under what circumstances does bearing witness create possibilities for redressing, rather than reinforcing, existing power structures?

Creating opportunities for ethical witnessing is relevant to embodied difference since, as disability scholars have noted, non-disabled people typically respond to disability in deeply emotional ways yet disability itself is largely ignored in affect studies (Goodley et al 2018). Further, healthcare emerges as a primary site of oppression for women with disabilities since as a group, they experience greater health inequities than disabled men and non-disabled women due to systemic barriers encounteredincluding inaccessible environments and invalidating attitudes and treatment—which render disabled women more vulnerable in healthcare systems and in the broader ableist society (Brownell et al., 2001; McColl et al., 2010). Healthcare encounters are complicated for racialized women with disabilities who confront confounding barriers related to the settler-colonial state's debilitating treatment of Indigenous and Black 
peoples that heighten vulnerabilities to mistreatment in (and beyond) healthcare. Settler-imposed socio-political regimes (structural racism, land theft, and forced confinement of Indigenous peoples on reserves and in residential schools leading to unsafe living conditions, well-documented abuses and genocide; and imposition of slavery and segregation onto Black peoples creating similar outcomes) have produced high degrees of debility among Indigenous and Black peoples, resulting in disproportionate impairment. As a result, the rate of disabilities experienced by Indigenous people is twice that of non-Indigenous people in Canada (BCANDS, 2017), whilst the reportedly high rates of disability among Black people in our nation remain woefully under-researched (Taylor \& Richards, 2019).

In contrast to disabled people, healthcare providers are systemically disciplined to present as invulnerable experts-learning to cloak or discount their disabilities and affective responses to disabled bodies during training and in practice (Viscardis et al., 2018). Disabled medical students, for example, face pervasive ableist pressures to perform invulnerable expert as they attempt to live up to two incommensurate narratives in medical school—that of the "good doctor", who prioritizes work, and the "good patient", who prioritizes getting well. This makes it impossible for trainees who occupy dual roles to succeed in either, leaving them grappling with the dilemma of whether they should prioritize self-care or their training (Stergiopoulos et al., 2018). Viscardis et al. (2018) report that identifying as disabled in the DST space comes with added vulnerability for disabled healthcare providers, who emphasize in their storywork various problematics associated with performing invulnerable expert. The binary between invulnerable "abled" expert and vulnerable "disabled" other becomes heightened as 
healthcare provider participants not only witness disabled people's traumatic healthcare stories but also their own. In this way, DST can create space for disabled and nondisabled healthcare provider and healthcare recipient storytellers to come together in order to share and witness stories that contend with ableist biomedical framings of human variation evident in clinical training and practice.

\section{Mobilizing New Meanings Methodology}

This study presents an analysis of a subset of data from the Mobilizing New Meanings study, which focused on transforming negative concepts of embodied difference. Housed within the Re•Vision Centre, this multi-site project was devised with the following objectives: i) generate new knowledge that might influence clinical concepts of disability/difference; ii) facilitate and analyze knowledge exchange processes between health practitioners and women with disabilities/differences using DST and research-based drama; iii) evaluate the impact and efficacy of practitioners' involvement in creating arts-based knowledge-exchange tools with women living with differences for shifting clinicians' self-reported attitudes, responses, and clinical competencies; and iv) evaluate the impact of viewing arts-based outputs on practitioner audiences' self-reported attitudes and perceived self-efficacy in clinical interactions. The research involved workshops where non-mutually exclusive groups of stakeholdersdisabled people, artists, healthcare providers, and researchers—talked back to received representations and made new meanings. In line with other Re・Vision projects, Mobilizing New Meanings was situated in the methodological tradition of critical artsbased research—which emphasizes political, participatory, and process-oriented approaches (Rice, 2020a) —and its main pulse was to bring together stakeholders from 
advantaged and disadvantaged groups to collaboratively re-story disability as difference—as potential rather than deficit (Rice \& Chandler, 2020).

Our research team was comprised of $30+$ stakeholders (students, artists, professors, and healthcare providers) with and without disabilities in three regions of Ontario (two smaller cities in Northern and Eastern Ontario, and one large city in Central Ontario). We approached disability in a non-deterministic way, purposefully leaving the category open for people to self-identify. Using a participatory approach, we invited team members to come into study activities as researchers and participants by attending a 3-day DST/multimedia storytelling workshop and making their own video. All had the option of receiving additional methods training, and later of co-facilitating regional workshops that involved both healthcare providers and recipients as participants (for details see Rice et al., 2015). Of participants and researchers who made videos, over $50 \%$ identified as disabled or living with a physical, mental, or sensory disability, approximately $25 \%$ as racialized, immigrants or Indigenous, and $25 \%$ as LGBTQ+. Healthcare providers included physicians, nurses, social workers, psychologists and care attendants.

Storytelling was important in this project because non-normatively embodied people have been, and continue to be, subject to stigmatizing labels, theories, and treatments within healthcare systems, causing harm and trauma, and ultimately leading to poor health outcomes (McColl et al., 2010). Studies show that women with disabilities have worse physical health, in part, due to not receiving preventive or screening services (Diab \& Johnston, 2004; Pharr \& Chino, 2013). Research also evidences what researchers call the "systematic invalidation" of disabled women in healthcare-routine 
practices that discount their experiential knowledge, characterize their complaints as psychosomatic and subject their bodies to painful interventions without forewarning or meaningful consent (Hassouneh-Phillips et al., 2005; Rice, 2014). It is common for disabled women who have had multiple surgeries to experience "medical trauma" due to the unattended effects (sensorial and emotional) of repeated invasive, painful treatments.

\section{Storytelling Method}

Using Re•Vision's mobile media lab, participants create multimedia stories, which are short videos that pair audio recordings of first-person stories with image- and soundscapes (photos, videos, artwork, music, utterances, gestures, etc.). Workshops include 12-15 participants and typically take place over the course of two to five days. Part of the story-making process is an in-depth framing of the themes/ issues that bring storytellers together. Participants gather in a story circle to share initial story ideas; participate in writing exercises to develop scripts; and have tutorials on editing software and access to full technical, writing, and conceptual support from script development to finished video. To conclude each workshop, participants can share their stories in a screening and everyone leaves the workshop as the creator of their own video. The 63 interviews include process-oriented reflections from those on the research team who elected to make their own videos, including researchers, workshop facilitators, students and community partners. Since all team members could opt to become participants by making their own video, and since some participants also became involved in the research (by co-writing and presenting on their videos), we identify interviewees as "participant-researchers" (Rinaldi et al., 2016). All those interviewed for this paper 
engaged in the story-making process described above, and interviews asked questions about experiences in making and sharing stories.

\section{Analysis}

The goal of analysis was to re-visit archival data in order to write a processoriented paper about DST generally, and the Mobilizing New Meanings project specifically. Out of an initial analysis of the process-oriented data emerged narratives related to the unique affective reflections of participant-researchers who engaged with the DST process, particularly reflections regarding affinity, vulnerability, sharing difficult experiences, and bearing witness to the difficult narratives of others. The findings we present are the result of an iterative data analysis approach, whereby stories about bearing witness across disability and difference emerged from the process-oriented data in unexpected ways. From there, we applied theory to the data to more fully capture and understand participants' experiences.

To develop familiarity with the content, Author 2 did a read through of the data; they then reviewed each interview carefully and used thematic analysis to draw out stories related to witnessing and relating across difference (Braun \& Clarke, 2006). After the initial analysis, Authors 1 and 3 reviewed the themes and all three authors began a second stage of analysis whereby they applied theory directly to the data, drawing on Indigenous and Black feminist and affect theory. Authors 1 and 2 returned to the data in this second stage of analysis, simultaneously applying theory and developing a framework for conceptualizing "affective, difference-attuned witnessing" within the DST methodology, as presented in the next section. 


\section{Findings}

In reflecting on the DST process, participant-researchers described key concepts related to difference-attuned witnessing. These include connectivity through shared creativity, vulnerability as risk and potentiality, and difficulty in expressing/sharing affectladen experiences within the DST process. We describe these reflections below, which help us to analyze the affective, difference attuned work of bearing witness in the DST process. All participant-researcher names are pseudonyms.

\section{Connectivity Through Shared Creativity}

One critical condition of possibility for affective witnessing across difference was the creative community forged through the DST process. Participants described this community as a safe( $r$ ) space in which they experienced welcoming, support, and intimacy. Some reported establishing a sense of connection with others who had navigated similar life experiences and challenges, including the challenge of creating a self-reflexive video in a short time. In this way, participants based the connections they formed not on identity solely but also on their shared experiences of writing, visualizing, assembling, and screening an original video within a few short days. They describe how going through an affectively charged and difference-attuned artistic process helped them to create a connected space where they could begin to trust and rely on each other. By rooting connectivity in the shared process of making art, their accounts suggest that the community created is based on a sense of "affinity" as much as (or rather than) of identity. 
It was very emotional and touching and I just felt a real warmth and fondness for everyone involved and I think that happens sometimes with the right combination of people, and the facilitation was so good, to create a safe and comfortable space, then there's a certain level of intimacy and risk-taking and sharing (Pat). Pat's use of the words "touching" and "emotional" bring to the fore the affective aspect of communities of affinity built through creative processes. This feeling is echoed by Alex:

It's a process that creates those communities. I potentially could have told my story in an hour, but the fact that those three days-it was quite intense, it was quite emotional—gave birth to those friendships which are now considered to be quite strong, and that community which I love and I'm very proud to be part of, it's very vibrant, hilarious disabled women that I've been through the process.

A number of participant-researchers discussed how they continued, or planned to continue, nurturing the community created after the research ended. For example, "There was a lot of peer support happening and intention to stay in contact, actually. I guess that goes back to the community building (Jamie)." While they intended to keep their connections alive outside the DST process, it is unclear whether this occurred for everyone after the project ended. For some, the shared experience of creating together and the affective bonds that formed through the creative process dissolved once the formal group dispersed after the research project concluded. For others, these bonds contributed to generative artistic, research, and other professional collaborations and to a broader disability arts movement (we take up this point in the discussion). Ultimately, the community created through the story-making process set the context for affective 
and difference-aware witnessing to occur, even if this community was for some, ephemeral.

\section{Sharing Experience}

Participant-researchers described the story circle as a moment of connecting with others' stories. These, oftentimes deep, connections were empowering and difficult for many:

I just didn't expect that it would affect me the way that it did. In both kind of a vulnerable way, but as well as feeling really connected with everybody and feeling like I've made a lot of really great friends (Sam).

Another participant-researcher noted:

There are so many really, very... personal and deep experiences shared in the group and some of the similarities of experience l've had...it was really hard to hear but it's also really_here's something to be said for having to having an experience that's shared like that, even though it's really unpleasant (Morgan).

This comment suggests that hearing one's experiences of vulnerability and pain reverberate in the experiences of others may be wounding, while also potentially validating as a source of connection. Relatedly, another participant-researcher described, "It's also a gift because as I learned to believe in myself, I stopped... being afraid of other people and I opened to the beauty of other people" (Lee). This "opening" oneself to the beauty of others echoes in other participants' descriptions of relating across difference. The following participant also used this idea of "opening" in 
describing the sense of acceptance, and even of embrace, they experienced in the group interactions:

By being accepted in a way... maybe not even accepted but embraced from the get-go, allowed me to open up in ways that I don't typically do in my day to day life, or it requires like a longer term kind of relationship building for me to unfold in that way (Donna).

For the following Indigenous participant, the act of witnessing through creativity was a point of healing and connection that far exceeded Western ideas about witnessing in a one-on-one teller/receiver dyad, providing space for polyvocal reconnections with their ancestors and life purpose more broadly, "I see art as medicine, I see digital storytelling as medicine. And telling your story so that they can be witnessed as medicine. So...it was about reconnecting with my ancestors and my purpose as an artist educator" (Erin).

\section{Difference-Attuned Empathy}

The following participant described bearing witnessing as a relational process of using empathy to attune to and affirm difference, in themselves and others:

I think it's about defusing the idea of the other. So that the other no longer is the other but there's an understanding of difference without collapsing difference. So I think that it's a great opportunity to engage with digital stories in terms of working through that in a multimodal medium where experiences are shared (Dana). 
This idea suggests that one can be a witness for another's as well as one's own pain, suffering, and strength. Further, it suggests witnessing requires an affirmative approach to difference, one which supplants notions of empathy that position the other as consumable, collapsible, or destructible. It gestures towards the idea that we can honour difference and the space between without othering. As we explore in the discussion section, collaborative storytelling methods, at their most intentional and careful, can allow for recognition of affinities in experiences without overriding asymmetries and uneven power relations across difference.

\section{Vulnerability as Risk and Potentiality}

Almost all participant-researchers experienced vulnerability, which many connected to feelings of connection, safety, and risk. They talked about how the DST process invited vulnerability, and how the safe(r) space created in the workshop generally and the connections made in the story circle specifically helped to mitigate their discomfort with vulnerability. One participant-researcher framed their capacity to be vulnerable as an "unfolding"-a relational experience of uncovering facilitated through group process and creative exploration:

I observed in myself this ability to unfold with the other participants. I really shared a lot of myself and that was kind of...unexpected in a way, actually, because I don't generally tend to open up so quickly but...I think it was a few different factors. The space is set up in a really safe way so there were ground rules set out and that was really helpful. It was helpful to be among other artists and writers and so that helps me to open up I think, as well (Petra). 
This "unfolding with" suggests a deeply relational aspect to bearing witness in the project's affective community. Vulnerability was also framed as risk-a risk that carries the potential for transformation and healing.

\section{Vulnerability as Risk}

A number of participants described the vulnerability of sharing one's story within the story-making process as "risky". They discussed risks associated with reflecting on one's own and others' pain/trauma, putting oneself in the center of one's story, and selectively sharing intimate details with others without knowing how these would be received.

There's definitely a risk whenever you're asking someone to sort of delve into their most personal experiences, opening up trauma or in bringing up triggers of experiences that are very... like even for me, I left there and went home and just felt very raw for a couple of days (Casey).

The risk of re-visiting trauma in a group setting is real and tangible for participantresearchers. At the same time, this participant described feeling like "there was every kind of support possible in that room". Another reflected:

...it feels very risky because you really are, and depending on the content of your story, telling, you're putting yourself in the center. And, you know, and then showing it to people and that's also a very vulnerable feeling and seeing how they'll respond (Robin).

This participant-researcher refers to putting oneself in the center-that is, telling and sharing one's story is active, and oftentimes difficult, work that puts focus and 
agency on the person holding the story. When one is at the center of the story, one is responsible for witnessing one's own story, and subsequently witnessing others' reactions to the story and the possible harm of others' responses. This simultaneous witnessing of self-and-other was unsettling for participant-researchers, and thus framed as one of the potential risks of shared vulnerability.

\section{Risk as Potentiality}

One participant-researcher astutely noted that in the risk of vulnerability exists the potential for transformative experience. In this description, opening oneself to the gaze of others-an inherently risky, vulnerable experience-creates an opportunity that is both uncomfortable and potentially transformative.

You're presenting yourself in a very unveiled fashion, so I think there's always a risk in doing that to some degree. And how people will respond and how they'll react and what they'll take away and what they'll learn from that experience as well. I think that's all a part in the risk. The risk is also the potentiality... within those challenges lie opportunities and possibilities for transformation. So it's like unsettling the settler within, so to speak? Or discomforting the comfort and comforting the discomfort (Robin).

This transformation may not be possible without the unsettling risk of vulnerability - that is, vulnerability that is not necessarily rooted in shared experiences or positionalities, but rather in the very act of vulnerable sharing, and witnessing the other and the other in the self. 


\section{Difficulty Sharing/Expressing Affect-Laden Experience}

Some participant-researchers described instances of difficulty with expressing emotion in a group context and of refusing the vulnerability that comes with selective disclosure of tender and painful experiences. A key aspect of this refusal was related to not knowing, in a context where power differentials were operating, how others-relative strangers - might react to storytellers' sharing of the often privatized and sometimes hidden parts of themselves.

Sitting in the storytelling circle process, I found that quite difficult to be that emotive and that open to sharing emotion in that way...that's the power difference; you're giving something of yourself away to people who at that point were strangers to me. I didn't know they were going to become friends and allies. At the beginning they were strangers, and that just felt a little bit odd. Even though the space is really safe and I knew it was a really productive space and a safe space. It just was difficult at the beginning (Alex).

Participant-researchers described hesitating to work at the hurt, tender, and unmapped edges of the self, in large part due to the different and often asymmetrical vulnerabilities emergent in the room. As has been written of vulnerability in the storytelling space: "Symmetrical vulnerability assumes sameness, which erases critically important differences in vulnerabilities as these materialize...in the entanglements of bodies and worlds. Asymmetrical vulnerability [in contrast]...seeks to understand differences in embodied vulnerabilities as produced by the intermingling of corporeal and social forces" (Rice \& Mündel, 2019, p. 134). Given that a sliding scale of vulnerability is produced through social, cultural and material forces, power differentials 
in vulnerability may not be possible to redress or overcome in the workshop space. Despite this, the DST space became an affectively-charged, difference-affirming community that both encouraged and complicated acts of bearing witness. Bearing witness, and the associated (asymmetrical) vulnerability/undoing, had the potential to create a transformative space for many participants. This potential speaks to the opportunities that emerge within an attuned-to-difference, affect-charged, arts-based research methodology.

\section{Concluding Discussion}

In making and sharing videos through Mobilizing New Meanings, healthcare providers, as participants and researchers, had the opportunity to bear witness to experiences of suffering, vulnerability, strength and creativity, both their own and others, and to work with disability identified researcher-participants to re-imagine disability together. This speaks broadly to the possibilities of art for transforming ableist relations and specifically of DST as an arts-based research method, wherein video-making becomes a creative avenue for discussing and desiring disability rights and justice (Rice et al. 2016). Arts-based research has the potential to disrupt highly regulated providerpatient interactions, as provider-participants, through exploring their interconnections with, come closer to disability, and through putting their self-discoveries in a video format (that exists outside of themselves) gain the critical distance needed to re/witness the vulnerable self, the vulnerable other, and power-relations scaffolding self-other relations-all in non-didactic ways. We believe the art-making process enabled healthcare provider-participants to enter a liminal or threshold space where they could safely question and generatively revision their interconnections with mindbody 
difference beyond the scripts of disability and other difference typically told using biomedical frames.

Through Mobilizing New Meanings, healthcare provider researcher-participants engaged with the arts in disability-positive spaces and recognized the assumptions underlying healthcare practice, the vulnerability of their own embodied lives (Viscardis et al., 2018). Their altered understandings of embodiment further held the potential to transform the care provided to disabled people. Unmasking one's vulnerability is a difficult task in a culture that socially excludes those who are produced and perceived as vulnerable. Yet the temporary affective space created in DST opened the possibility for participants to share themselves in oftentimes vulnerable ways, disrupting dominant norms and promoting transformation/healing. The transformative potential of vulnerability is tangible for disabled participant-researchers through creating and retelling their own stories. Similarly, vulnerability is a powerful practice for participantresearchers in privileged positions (e.g., healthcare providers) to "unmask their vulnerabilities in an effort to deepen understanding and expose the operations of power in social situations and relations" (Rice et al., 2015, p. 10). Our findings suggest that the risk of vulnerability is potentially both unsettling and transformative. In DST, participants engage across difference and share their lived realities_-including pain, tenderness, and resistance-with others, and to engage in the collective practice of making and telling stories. Doing this vulnerable work required participant-researchers to take risks, and to approach the other within the context of ethical spaces of engagement through embodied, affective listening/attending to (Ermine, 2007; Maracle, 2015). 
The current study sought to theorize experiences of difference- and affectattuned witnessing in a temporary affective community constructed through arts-based research. Our analysis suggests that connectivity and vulnerability are key conditions of possibility for witnessing self and other, and that creating/sustaining an affective community across differences and uneven power relations requires a level of safety and respect to foster such unguarded relationality. The prominence of vulnerability in participants' reflections suggests that bearing witness, as an embodied, affect-charged act, both requires and generates feelings of exposure, openness to the other, and undoing of the self. The potentiality of vulnerability expressed by participants complements feminist theoretical analysis of vulnerability as a necessary, inherent part of embodied humanity - a view that runs contrary to classic liberal and neoliberal constructions of the autonomous, self-sufficient citizen (Fineman, 2008). This vulnerability may be more acutely felt in affectively charged communities such as within the digital story-making process (Ahmed, 2004). Affect circulates within the process of difference-attuned witnessing, whereby the person sharing testimony "unfolds", making themselves vulnerable to the self/other/witness/co-witness. This vulnerability is acknowledged to be asymmetrical along lines of power relations (economically, politically and socially) that produce some bodyminds as more vulnerable than others. At the same time, it holds the potential for transformation and healing, when the witness engages ethically with an acknowledgement of power dynamics and an orientation toward a common, justice-oriented goal.

In the current study, DST provided an affectively charged space that both encouraged and complicated acts of witnessing. Participants' descriptions of unfolding, 
vulnerability, and the potential inherent therein suggest that DST, as an art-making practice, can foster ethical engagement across difference. Through acts of differenceattuned witnessing, DST may address Nash's $(2013,2019)$ call for affective communities that redress rather than reinforce current power structures. Nash (2019) notes that reciprocal vulnerability and witnessing are foundational to the Black feminist practice of love politics, which pivot around selective self-disclosure of invisibilized oppression as a pathway to making connections and movement-building across difference. Such selective self-disclosure is observed repeatedly throughout the DST process. Participants make decisions about whether, when, and how to make themselves vulnerable during the story circle, again when they decide what to include in (and edit out of) their stories, and once again when they decide whether to screen their videos during and after the workshop. This practice of love politics fosters community but it requires the careful setup of a justice-oriented space. For example, the storytelling workshops in the current study began with an opening and introduction of Indigenous storytelling methods by an Indigenous scholar and followed with presentations by disabled scholars about the ways that disability is typically storied in healthcare and society, and how disability studies and activisms story disability differently. In this way, bearing witness within the affective community of DST holds potential, and also requires justice-infused intention and difference-attuned care.

The affective community fostered within DST workshops was ephemeral (Rice et al., 2016). In disability-positive spaces of feminist arts-based research, difference was embraced; however, when the workshops ended, the community dispersed into a normative culture and healthcare system where ableist logics continue to circulate and 
where ableism continues to manifest in environments. Despite this, the project did contribute to developing a disability arts movement in Canada, including by providing the space, tools, equipment and opportunity for disability-identified researchers, artists and activists to come together to question the marginal positioning of disability, Mad and d/Deaf arts in art history and the contemporary art world (Chandler et al., 2018). Furthermore, drawing from Richardson and Schankweiler's (2019) concept of the cowitness (i.e., those who see the digital testimony after the fact), there is potential for the affective community to grow indefinitely as people continue to engage with the published stories beyond the immediate study, which in turn suggests that opportunities for difference-attuned witnessing and empathy might be endless.

Conceptions of empathy rooted in sameness and in mainstream psychology's universalist drive to map the normative mind have been critiqued (Boler, 1997), yet the concept of empathy holds potential for engaging across difference and imagining a more just society. Empathy deserves attention within affect-charged, difference-attuned collective spaces of mutual (though asymmetrical) vulnerability and shared creativity. We expand Richardson \& Schankweiler's (2019) conceptualization of affective witnessing by suggesting a difference-attuned approach to empathy that fosters spaces of ethical engagement and embodied listening in Maracle's (2015, p. 21) terms, "with all of one's senses" can create the conditions of possibility for mutual witnessing. This approach to empathy requires the listener/perceiver to recognize their implicatedness in the psychic and material realities of the person sharing testimony (Maracle, 2015; Rice, 2009; Yuval-Davis, 1997). Supporting participant-makers in the creation of video testimony with the help of artists and videographers allows people to work at the edges 
of their comfort and distill experiences into dense affective snapshots that encapsulate the makers' felt knowledge. In addition to the creative, multi-sensory elements of this genre, its durable format allows, as Richardson and Schankweiler (2019) have argued, for witnessing to occur in the time of the telling (in the workshop), the making (as makers compose their videos), the viewing (at the end of each workshop) and subsequent viewings (with self and others in public and private spaces) thus opening possibilities for transformational change beyond the workshop space. Multiple opportunities to bear witness to self and other with embodied, difference-attuned empathy thus hold potential for healing and transformation within affective, differenceattuned communities that are created within arts-based research.

\section{Funding Acknowledgement}

This manuscript reports on findings from a larger Canadian Institutes of Health Research-funded study entitled Mobilizing New Meanings of Disability and Difference: Using Arts-Based Approaches to Advance Healthcare Inclusion for Women with Disabilities. Grant \# MP0106597. 


\section{References}

Ahmed, S. (2004). The cultural politics of emotion. Edinburgh University Press.

Ahmed, S., \& Stacey, J. (2001). Testimonial cultures: An introduction. Cultural Values, 5, 1-6. https://doi.org/10.1080/14797580109367217

Archibald, J. (1997). Coyote learns to make a storybasket: The place of First Nations stories in education. [Doctoral dissertation]. Faculty of Education. Vancouver: University of British Columbia.

Boler, M. (1997). The risks of empathy: Interrogating multiculturalism's gaze. Cultural Studies, 11, 253-273. https://doi.org/10.1080/09502389700490141

Boler, M. (1999). Feeling power: Emotions and education. Routledge.

Bonds, A., \& Inwood, J. (2016). Beyond white privilege: Geographies of white supremacy and settler colonialism. Progress in Human Geography, 40(6), 715733. https://doi.org/10.1177/0309132515613166

BCANDS (British Columbia Aboriginal Network on Disability Society), (2017). BCANDS Accessibility Consultation Report. National Indigenous Federal Accessibility Legislation Consultation. Victoria, BC: BCANDS.

Brownell, M. D., Roos, N. P. \& Roos, L. L. (2001). Monitoring health reform: A report card approach. Social Science and Medicine, 52(5) 65770. https://doi.org/10.1016/s0277-9536(00)00168-4

Butler, J. (2004). Undoing gender. Routledge.

Carter, J. (2015). Discarding sympathy, Disrupting catharsis: The mortification of Indigenous flesh as survivance-intervention. Theatre Journal, 67(3), 413-32. https://doi.org/10.1353/tj.2015.0103. 
Chandler, E., Changfoot, N., Rice, C., LaMarre, A., \& Mykitiuk, R. (2018). Cultivating disability arts in Ontario. Review of Education, Pedagogy, and Cultural Studies, 4O(3), 249-264. https://doi.org/10.1080/10714413.2018.1472482

Diab, M. E., \& Johnston, M. V. (2004). Relationships between level of disability and receipt of preventive health services. Archives of Physical Medicine and Rehabilitation, 85(5), 749-757. https://doi.org/10.1016/j.apmr.2003.06.028

Douglas, P., Rice, C., \& Siddiqui, A. (2020). Living dis/artfully with and in illness. Journal of the Medical Humanities, 41(1), 395-410. https://doi.org/10.1007/s10912-01909606-5

Douglas, P., Rice, C., Runswick-Cole, K., Easton, A., Gibson, M., Gruson-Wood, J., Klar, E., \& R., Shields (2019). Restorying autism: A body becoming disability studies in education approach. Journal of Inclusive Education, 1-18. https://doi.org/10.1080/13603116.2018.1563835

Ermine, W. (2007). The ethical space of engagement. Indigenous Law Journal, 6, 193203. https://doi.org/10.1007/978-94-024-1179-9_300500

Fineman, M. A. (2008). The vulnerable subject: Anchoring equality in the human condition. Yale Journal of Law and Feminism, 20, 1-23.

Goodley, D., Liddiard, K. \& Runswick-Cole, K. (2018). Feeling disability: Theories of affect and critical disability studies, Disability \& Society, 33 (2), 197-217.

Gray, B. (2011). Empathy, emotion and feminist solidarities. Critical Studies, 34, 207232. https://doi.org/10.1163/9789042032422_011 
Hassouneh-Phillips, D., McNeff, E., Powers, L., \& Curry, M. A. (2005). Invalidation: A central process underlying maltreatment of women with disabilities. Women \& Health, 41(1), 30-50. https://doi.org/10.1300/J013v41n01_03

Maracle, L. (2015). Memory serves: Oratories. NeWest Press.

McColl, M. A., Jarzynowska, A., \& Shortt, S. E. D. (2010). Unmet health care needs of people with disabilities: Population level evidence. Disability \& Society, 25(2), 205-218. https://doi.org/10.1080/09687590903537406

McGloin, D. (2015). Listening to hear: Critical allies in Indigenous Studies. Australian Journal of Adult Learning, 55, 267 - 282.

Mansbach, D. (2016). Witnessing as activism: Watching the other at the Israeli checkpoints. Journal of Human Rights, 15, 496-508. https://doi.org/10.1080/14754835.2015.1062720

Nash, J. C. (2013). Practicing love: Black feminism, love-politics, and postintersectionality. Meridians, 11, 1-24. https://doi.org/10.2979/meridians.11.2.1

Nash, J. C. (2019). Black Feminism Reimagined: After Intersectionality. Duke University Press.

Oliver, K. (2004). Witnessing and testimony. Parallax, 10, 78 - 87. https://doi.org/10.1080/1353464032000171118

Oliver, K. (2015). Witnessing, recognition, and response ethics. Philosophy \& Rhetoric, 48, 473-493. https://doi.org/10.5325/philrhet.48.4.0473

Recollet, K. (2015). Glyphing decolonial love through urban flash mobbing and 'Walking with Our Sisters'. Curriculum Inquiry 45(1), 129-45. https://doi.org/10.1080/03626784.2014.995060 
Rice, C. (2009). Imagining the other? Ethical challenges of researching and writing women's embodied lives. Feminism \& Psychology, 19, 245 - 266. https://doi.org/10.1177/0959353509102222

Rice, C., (2014). Becoming women: The embodied self in image culture. UT Press.

Rice, C. (2018). Volatile bodies and vulnerable researchers: The risks of embodiment research. In S. Batacharya \& R. Wong, (Eds.) Sharing Breath: Embodiment, Pedagogy and Decolonization (pp. 135-160). AU Press.

Rice, C. (2020). Digital storytelling. In Crawford, P., Brown, B., \& Charise, A., (Eds.), Companion for Health Humanities. Taylor \& Francis.

Rice, C., \& Chandler, E. (2020). Representing difference: Disability, digital storytelling, and public pedagogy. In K. Ellis, G. Goggin, B. Haller \& R. Curtis (Eds.). Routledge Companion to Disability and Media (pp. 377-387). Routledge.

Rice, C., Chandler, E., \& Changfoot, N. (2016). Imagining otherwise: The ephemeral spaces of envisioning new meanings. C. Kelly \& M. Orsini (Eds.). Mobilizing Metaphor (pp. 54-75). UBC Press.

Rice, C., Chandler, E., Harrison, E., Liddiard, K., \& Ferrari, M. (2015). Project Re•Vision: Disability at the edges of representation. Disability \& Society, 30, 523-527. https://doi.org/10.1080/09687599.2015.1037950

Rice, C., Chandler, E., Rinaldi, J., Liddiard, K., Changfoot, N., Mykitiuk, R., \& Mündel, I. (2017). Imagining disability futurities. Hypatia, 32(2), 213-229. https://doi.org/10.1111/hypa.12321 
Rice, C., Chandler, E., Liddiard, K., Rinaldi, J., \& Harrison, E. (2018). The pedagogical possibilities for unruly bodies. Gender \& Education, 30(5), 663-682. https://doi.org/10.1080/09540253.2016.1247947

Rice, C., \& Mündel, I. (2018). Storymaking as methodology. Canadian Review of Sociology, 55(2), 211-31. https://doi.org/10.1111/cars.12190

Rice, C., \& Mündel, I. (2019). Multimedia storytelling methodology: Notes on access and inclusion in neoliberal times. Canadian Journal of Disability Studies, 8(2), 118146. https://doi.org/10.15353/cjds.v8i1.473

Rice, C., Harrison, E., \& Friedman, M. (2019). Doing justice to intersectionality in research. Cultural Studies <=> Critical Methodologies. 19(6), 409-420. https://doi.org/10.1177/1532708619829779

Rice, C., Dion, S., Mündel, I., \& Fowlie, H. (2020b). Re/Turning the gaze: Unsettling settler logics through Multimedia Storytelling. Feminist Media Studies, 1-19. https://doi.org/10.1080/14680777.2019.1707256

Rice, C., LaMarre, A., Changfoot, N., \& Douglas, P. (2020a). Making spaces: Multimedia storytelling as reflexive, creative praxis. Qualitative Research in Psychology 17 (2), 222-239, https://doi.org/10.1080/14780887.2018.1442694 Rinaldi, J., Rice, C., LaMarre, A., Pendleton Jiménez, K., Harrison, E. Friedman, M., McPhail, D., Robinson, M., \& Tidgwell, T. (2016). Through Thick and Thin. Psychology of Sexualities Review (PoSR), 7(2), 63-77. https://shop.bps.org.uk/publications/publication-by-series/psychology-ofsexualities-review/psychology-of-sexualities-review-vol-7-no-2-winter-2016.html 
Richardson, M., \& Schankweiler, K. (2019). Affective witnessing. In J. Slaby \& C. von Scheve (eds.). Affective societies: Key concepts (pp. 166-177). Taylor \& Francis Group.

Silverman, K. (1996). The threshold of the visible world. New York: Routeledge.

Stergiopoulos, E., Fernando, O., \& Martimianakis, M. (2018). "Being on both sides": Canadian medical students' experiences with disability, the hidden curriculum, and professional identity construction. Academic Medicine, 93, 1550-1559. https://doi.org/10.1097/acm.0000000000002300

Taylor, D., \& Richards, D. (2019). Triple jeopardy: Complexities of racism, sexism, and ageism on the experiences of mental health stigma among young Canadian Black Women of Caribbean descent. Frontiers in Sociology, 4(43), 1-10. https://doi.org/10.3389/fsoc.2019.00043

Yuval-Davis, N. (1997). Gender \& Nation. Sage Publications.

Viscardis, K., Rice, C., Pileggi, V., Underhill, A., Changfoot, N., \& Chandler, E. (2018). Difference within and without. Qualitative Health Research, 29(9), 1287-1298. https://doi.org/10.1177/1049732318808252

\section{Biographical Note}

Carla Rice: Is Professor and Canada Research Chair in the College of Social and Applied Human Sciences and Founding Director of the Re•Vision Centre for Art and Social Justice at the University of Guelph. She specializes in disability and embodiment studies and in arts-based research methodologies with a focus on changing systems and fostering social well-being and justice. 
Katie Cook: Is a doctoral candidate in the Community Psychology program at Wilfrid Laurier University in Waterloo, Ontario. Katie's research engages feminist affect theory alongside narrative and arts-based methods to understand the intergenerational movement and effects of weight-based stigma.

K. Alysse Bailey: Is a postdoctoral fellow at the University of Guelph. Her research involves the use of arts-based and participatory research methodologies to challenge dominate fitness industry narratives through a revisioning of 'fitness' by centering non-normative embodied ways of being. 